\title{
Association Between Mothers' Problematic Internet Use and the Thinness of Their Children
}

\author{
Aya Sakakihara, $\mathrm{PhD},{ }^{1}$ Chiyori Haga, $\mathrm{PhD}{ }^{2}$ and Yoneatsu Osaki, MD, $\mathrm{PhD}^{3}$
}

\begin{abstract}
This study aimed to clarify the association between mothers' problematic Internet use (PIU) and the thinness of their children. We analyzed data collected from health examinations of young children aged 4 months, 1.5 years, and 3 years of age performed in Matsue city, Japan, between April 2016 and March 2017. The subjects comprised 1,685 (866 boys, 819 girls) children aged 4 months, 1,728 (898 boys, 830 girls) aged 1.5 years, and 1,672 (802 boys, 870 girls) aged 3 years. Logistic regression analysis was used to clarify the association between mothers' PIU (Young's Diagnostic Questionnaire for Internet Addiction score: $\geq 4$ ) and the thinness (body mass index: $<15$ ) of their children after adjusting for covariates such as birth weight, nutritional form, parental smoking status, maternal age, skipping breakfast, eating snacks, sleeping late, outdoor play, and daytime caregiver. Analysis after stratification by sex and age revealed that the mothers' PIU was significantly associated with their children's thinness only in boys aged 4 months or 1.5 years (odds ratio $[\mathrm{OR}]=3.16,95 \%$ confidence interval $[\mathrm{CI}]=1.00-9.96$ and $\mathrm{OR}=2.68,95 \% \mathrm{CI}=1.04-6.89$, respectively). Mothers' PIU may promote thinness among boys aged $<3$ years. As the nutritional status of children aged $<3$ years is affected by maternal feeding attitudes, our findings suggested that mothers who exhibit PIU do not provide adequate care for their children, particularly regarding feeding. In contrast, no association between mothers' PIU and their children's thinness was observed in girls.
\end{abstract}

Keywords: problematic Internet use, child development, thinness, body mass index

\section{Introduction}

$\mathbf{I}^{\mathrm{r}}$

NTERNET ACCESS HAS RAPIDLY INCREASED in recent years, enhancing the quality of life related to communication, education, businesses, recreation, and many other aspects. On the contrary, there are concerns with users developing problems in interpersonal relationships and social life because of difficulty in controlling Internet use. ${ }^{1}$ Such a condition is known as "problematic Internet use (PIU)" and has drawn global attention since 1995 as a relatively new disorder. ${ }^{2-4}$

Several terms have replaced PIU such as "Internet addiction," "Internet dependency," "compulsive Internet use," "pathological Internet use," and "compulsive computer use., This study consistently regarded "PIU" as a condition of being absorbed in the Internet and developing consequent problems in social life. Several investigators have reported that PIU may have many adverse consequences, including less than regular exercise, skipping meals, and late bedtimes, ${ }^{6}$ resulting in obesity and being overweight ${ }^{7-9}$ or underweight. ${ }^{7}$ However, all the aforementioned studies involved adolescents, and only a few studies have examined adult PIU, ${ }^{10-12}$ subsequently reporting an adult PIU prevalence rate of $4.0 \%-6.2 \%$. Although the prevalence rate of adolescent PIU is $6.0 \%,{ }^{13}$ which has been drawing attention, some researchers warn against underestimating adult PIU. ${ }^{12}$

The number of studies focusing on PIU among pregnant women and mothers is even smaller. Accordingly, Fujioka et al. ${ }^{14}$ examined mothers aged $\geq 20$ years using the Young's Internet Addiction Test ${ }^{15}$ during health examinations for children aged 1.5 years, and reported that $2.8 \%$ of these mothers were suspected to be problematic users. In addition, they clarified that the level of Internet addiction increases with negative emotions related to parenting, represented by a sense of parenting burden and anxiety. In another previous study, the

${ }^{1}$ Community Health Nursing, Faculty of Medicine, Shimane University, Izumo, Japan.

${ }^{2}$ Community Health Nursing, Graduate School of Health Sciences, Okayama University, Okayama, Japan.

${ }^{3}$ Division of Environmental and Preventive Medicine, Faculty of Medicine, Tottori University, Yonago, Japan.

(C) Aya Sakakihara et al. 2019; Published by Mary Ann Liebert, Inc. This Open Access article is distributed under the terms of the Creative Commons License (http://creativecommons.org/licenses/by/4.0), which permits unrestricted use, distribution, and reproduction in any medium, provided the original work is properly cited. 
prevalence rates of PIU among women aged 16-29 and 30-39 years were $1.7 \%$ and $1.4 \%$, respectively. ${ }^{10}$ Moreover, the rate among female university students who may become mothers in the near future has been markedly varied among studies, for example, from $4 \%{ }^{16}$ to $28.7 \%,{ }^{17} 31.7 \%,{ }^{18}$ and $35.8 \%,{ }^{19}$ indicating the necessity for further investigation of mothers' PIU.

Mothers' PIU may lead to inadequate parenting and carries the risk of interfering with the normal development of their children. Previous studies have explained this through consequent problems such as little sleep and failure to eat for long periods. $^{6,20}$ Regarding PIU during parenting, there are concerns over the increased risk of neglect. Indeed, in a case study by Young, ${ }^{1}$ one mother was engrossed in the Internet to the extent that she neglected cooking, cleaning, shopping, and other household duties, consequently making her children feel neglected. Such a situation may even disrupt the family. In a study by Oka et al., ${ }^{21}$ parental PIU led to sleep disorders in not only the parents themselves but also in their children, negatively influencing the latter's emotions and behaviors. Considering that PIU among mothers leads to insufficient parenting, such as neglect, their children may become thin in addition to developing sleep disorders. A previous study demonstrated that PIU leads to problematic eating habits associated with being underweight, including decreased dietary intake and/or appetite, and skipping dinner. ${ }^{7}$ Therefore, this study focused on children's body size as an index of their health conditions to examine the association between mothers' PIU and their children's thinness. The clarification of such an association may provide a basis for confirming whether the former leads to inappropriate parenting or even child abuse.

\section{Methods}

\section{Study design and data sources}

In 2017, a cross-sectional study was conducted in Matsue city, Shimane prefecture, to analyze data from health examinations of children aged 4 months, 1.5 years, and 3 years. Matsue city is a provincial city with a population size of $\sim 200,000$ and birth rate of 1,700 births per year. The data were provided by Matsue city after integrating the mothers' responses to the Young's Diagnostic Questionnaire for Internet Addiction (YDQ) ${ }^{22}$ collected during the health examinations and their children's results using unlinkable anonymization. Accordingly, 1,733 children aged 4 months (participation rate: $99.5 \%), 1,798$ aged 1.5 years $(98.3 \%)$, and 1,754 aged 3 years $(97.9 \%)$ were included.

The exclusion criteria included the following: multiple births that increase the risks of malnutrition and being underweight ${ }^{23}$ (4 months: 22, 1.5 years: 26, and 3 years: 28 ), extremely low birth weight $(<1,000 \mathrm{~g})$ that may lead to underdevelopment ${ }^{24}$ (1.5 years: 1 and 3 years: 2 ), child abuse because of the mother's own mental disorder/developmental disability or infant home use because of parenting difficulty (4 months: 10 and 1.5 years: 9), and YDQ respondents other than mothers (4 months: 16, 1.5 years: 34 , and 3 years: 52). As children with severe diseases or disabilities are managed by medical institutions, they did not participate in health examinations. Consequently, 1,685 (866 boys, 819 girls) children aged 4 months, 1,728 (898 boys, 830 girls) aged 1.5 years, and 1,672 (802 boys, 870 girls) aged 3 years were included in the study.

Matsue city provided the data after removing personal identification information, including the name, address, and birth date, and supplementing ID numbers. This study was approved by the Ethics Committee of the School of Medicine, Shimane University (approval number: 2519).

\section{Measurements}

Thinness among children was assessed using the body mass index (BMI) (weight $[\mathrm{kg}] /$ height $[\mathrm{m}]^{2}$ ). As many countries have individually created a BMI chart for each age group, the cutoffs vary. ${ }^{25}$ Using the standard body size of children based on a BMI of $15-19^{26}$ in Japan, this study defined thinness as a BMI of $<15$.

PIU was assessed using the YDQ, ${ }^{22}$ a scale consisting of eight questions regarding the pathological gambling criteria defined in the Diagnostic and Statistical Manual, 4th Edition $(D S M-I V)$ that are answered with $<$ Yes/No $>$. We used the YDQ in this study because it is one of the most widely used PIU assessment scales. ${ }^{2,3,13,27,28}$ Furthermore, it has previously been used in surveys involving adult women, ${ }^{10}$ and demonstrated to have acceptable reliability and consistency, as represented by a Spearman-Brown coefficient of 0.729 for split-half reliability, Cronbach's alpha of 0.713 with a standardized item alpha of $0.759,{ }^{29}$ and Cronbach's alpha of $0.789 .^{30}$ Based on this scale, respondents who answered $<$ Yes $>$ to five or more of the eight questions were classified as addicted Internet users. Moreover, to screen for at-risk Internet users, YDQ scores of 3-4 were used as a criterion. ${ }^{10,29}$ Only those who answered all the YDQ questions in this study were analyzed. The Cronbach's alpha of the YDQ in our study was $0.546-0.645$.

\section{Covariates}

Previous studies have found that birth weight, ${ }^{31-33}$ maternal age, ${ }^{31}$ parental smoking, ${ }^{34,35}$ and financial status ${ }^{33,36,37}$ are mainly associated with thinness in children. Factors associated with their body size included nutritional form, ${ }^{38,39}$ daytime caregiver, ${ }^{40,41}$ breakfast, ${ }^{42,43}$ duration of sleep, ${ }^{44}$ snacks, ${ }^{43,44}$ and physical activity. ${ }^{44,45}$

Based on the aforementioned findings, the following items were used as covariates to analyze children aged 4 months: birth weight (low birth weight: $<2,500 \mathrm{~g}$ or others: $\geq 2,500 \mathrm{~g}$ ), nutritional form (breastfeeding only, formula feeding, or breast and formula feeding), mother's current smoking status (nonsmoking or smoking), father's current smoking status (nonsmoking or smoking), maternal age (normal: 20-34 years, elderly: $\geq 35$ years, or young: $\leq 19$ years), and daytime caregiver (mother or others). Although parental smoking itself is associated with children's body size, this study used this variable considering that it also reflects the parental socioeconomic status because smoking rates are higher among individuals in lower socioeconomic positions. ${ }^{46}$ For children aged 1.5 and 3 years, skipping breakfast, eating snacks, sleeping late, and playing outdoors were also used in addition to the covariates used for those aged 4 months, excluding nutritional form. Multivariate analysis confirmed the multicollinearity among these variables.

\section{Statistical analysis}

The children's characteristics were examined by calculating their numbers and proportions based on age and sex. The $\chi^{2}$ test was conducted for each sex to clarify sex differences among somatotypes and associated factors. 
Subsequently, the association between mothers' PIU and thinness of their children was examined based on sex and age in months. As only $\sim 1 \%$ had a YDQ score $\geq 5$, the cutoff was set at 4. Logistic regression analysis was performed with children's thinness $(\mathrm{BMI}<15)$ as the dependent variable and mothers' PIU (YDQ $\geq 4$ ) as the explanatory variable while incorporating the aforementioned covariates. Univariate logistic regression analysis was initially performed, followed by multivariate logistic regression analysis for two models: Model 1 incorporating birth weight and nutritional form (only the former for children aged 1.5 and 3 years) and Model 2 incorporating mother's current smoking status, father's current smoking status, maternal age, daytime caregiver, breakfast, bedtime, snacks, outdoor play, and daytime caregiver (only the current smoking status of the mother and father, maternal age, and daytime caregiver were incorporated for children aged 4 months).

Sensitivity was analyzed using the data, assigning a score of 0 to questions without answers, to confirm changes in the results.

IBM SPSS Statistics 22 was used for the analysis, with the significance level set at $<5 \%$.

\section{Results}

The characteristics of the children aged 4 months, 1.5 years, and 3 years are given in Table 1. The proportions of children with BMI $<15$ among children aged 4 months, 1.5 years, and 3 years were $7.3 \%, 14.6 \%$, and $29.4 \%$, respectively. Significant sex differences were found in BMI values for children aged 4 months or 1.5 years. Moreover, $2.8 \%$, $3.2 \%$, and $3.1 \%$ of mothers with children aged 4 months, 1.5 years, and 3 years had a YDQ score of $\geq 4$, respectively.

As given in Tables 2-4, univariate logistic regression analysis found that the mothers' PIU was significantly correlated with their children's thinness in boys aged 4 months and 1.5 years (odds ratio $[\mathrm{OR}]=2.85,95 \%$ confidence interval $[\mathrm{CI}]=0.95-8.57$ and $\mathrm{OR}=3.67,95 \% \mathrm{CI}=1.55-8.69$, respectively). However, no significant correlation was observed between thinness in boys aged 3 years old and their mothers' PIU $(\mathrm{OR}=1.23,95 \% \mathrm{CI}=0.50-3.07)$. Furthermore, no significant correlation was found between thinness in girls aged 4 months, 1.5 years, or 3 years and their mothers' PIU $(\mathrm{OR}=1.23,95 \%$ $\mathrm{CI}=0.50-3.07 ; \mathrm{OR}=1.45,95 \% \mathrm{CI}=0.61-3.47$; and $\mathrm{OR}=1.37$, 95\% CI $=0.64-2.94$, respectively). The multivariate logistic regression analysis provided similar results. The mothers' PIU was found to be significantly correlated with their children's thinness in boys aged 4 months or 1.5 years $(\mathrm{OR}=3.16,95 \%$ $\mathrm{CI}=1.00-9.96$ and $\mathrm{OR}=2.68,95 \% \mathrm{CI}=1.04-6.89$, respectively). However, no significant correlation was found between thinness in boys aged 3 years and their mothers' PIU $(\mathrm{OR}=0.66,95 \% \mathrm{CI}=0.14-3.20)$. Furthermore, no significant correlation was observed between thinness in girls aged 4 months, 1.5 years, and 3 years and their mothers' PIU $(\mathrm{OR}=0.58,95 \% \mathrm{CI}=0.07-4.55 ; \mathrm{OR}=1.27,95 \% \mathrm{CI}=0.51-$ 3.18 ; and $\mathrm{OR}=1.25,95 \% \mathrm{CI}=0.48-3.24$, respectively). The sensitivity analysis yielded similar results.

\section{Discussion}

Our study demonstrated an association between mothers' PIU and the thinness of their children. Although many previous studies focused on adolescent PIU, ${ }^{12,47}$ and mainly examined the prevalence of PIU, diagnostic criteria for PIU, the association between PIU and mental health, and risk factors for PIU, ${ }^{47-49}$ this study may be important in that it clarified not only the prevalence of PIU among mothers, but also problems because of their PIU. Among mothers rearing children, those with a YDQ score $\geq 5$ or 4 accounted for $\sim 1 \%$ and $3 \%$ of the total subjects, respectively. Fujioka et al. ${ }^{14}$ using YIAT $20{ }^{15}$ found that PIUs accounted for $2.8 \%$, which is close to the rate of a YDQ score $\geq 4$ in our study. Similar values were also reported by Bakken et al. ${ }^{10}$ using the YDQ, ${ }^{22}$ with women having a YDQ score of $\geq 5$ or 3-4, accounting for $1.4 \%$ (aged 30-39 years) - 1.7\% (aged 16-29 years) and $4.8 \%-13.1 \%$, respectively. Thus, a PIU prevalence rate of $1 \%-3 \%$ among mothers may be a useful criterion for future studies.

The prevalence of thinness was 3.16 and 2.68 times higher among boys aged 4 months and 1.5 years, respectively, when their mothers had a YDQ score of $\geq 4$. Children aged 4 months are within the lactation period, whereas children aged 1.5 years cannot independently ingest nutrients. Therefore, thinness in such children may be because of insufficient nutrient intake as a result of poor parenting by their mothers who are absorbed in the Internet. Moreover, several previous studies revealed the association between adolescent PIU and skipping meals ${ }^{6,20}$ and decreased dietary intake and/or appetite, which can lead to being underweight. ${ }^{7}$ This suggests that mothers with PIU are thin because of insufficient dietary intake, and as thinness in parents is associated with thinness in their children, ${ }^{50,51}$ there may be an association between mothers' PIU and thinness in their children. As parental PIU has been reported to cause sleep disorders in both parents and their children, ${ }^{21}$ this study may have significance in suggesting the direct and indirect negative influences of PIU on the users themselves and those around them, respectively.

Furthermore, the association between mothers' PIU and thinness was only observed in boys and not in girls. This may be explained by higher total energy expenditure ${ }^{52-54}$ and requirements ${ }^{54}$ for male infants and toddlers. Thus, the effects of insufficient nutrient and energy intakes may have consequently been more marked on boys than on girls, resulting in a higher prevalence of thinness among the boys. In contrast, there was no association between mothers' PIU and thinness in children aged 3 years regardless of sex. At this age, children are able to independently ingest nutrients and many go to nursery school. Moreover, the daytime caregiver was not the mother in $85.8 \%$ of the cases. Consequently, the influence of mothers' PIU on parenting may have been less marked.

This study had the following limitations. First, given the cross-sectional design of this study, causal relationships were unable to be clarified. Therefore, cohort studies should be conducted in the future to examine whether a similar tendency is observed in other populations by confirming the consistency and strength of association involving a larger number of samples, while considering the temporal relationship as an element of causal inference. However, thinness among children is highly unlikely to lead to PIU in their mothers, whereas maternal PIU may be more a reasonable cause of thinness in their children. Second, considering that mothers with a YDQ score of $\geq 4$ accounted for $\sim 3 \%$ of the sample, such a small sample size may have resulted in beta errors. However, an association was found, suggesting 


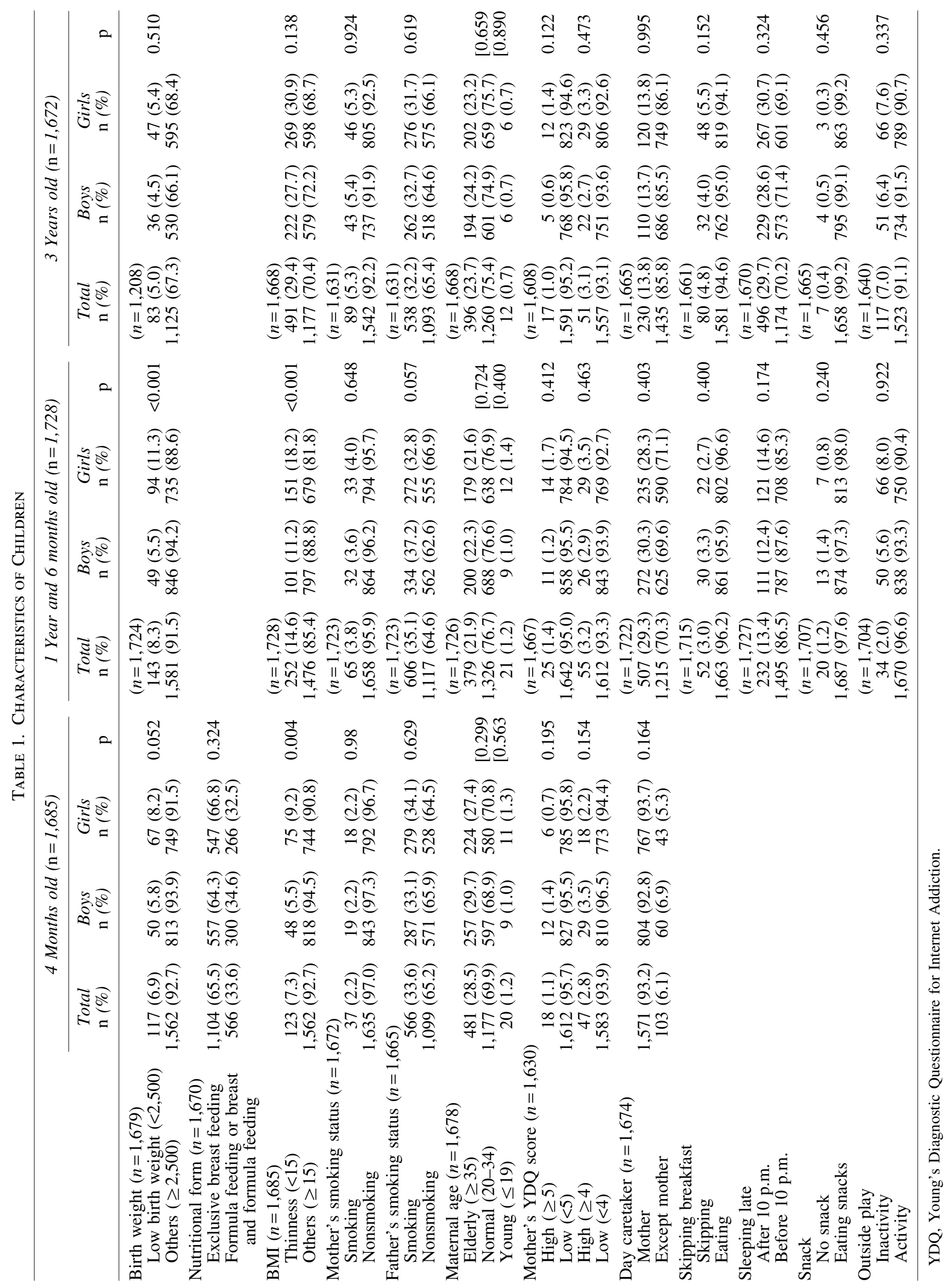




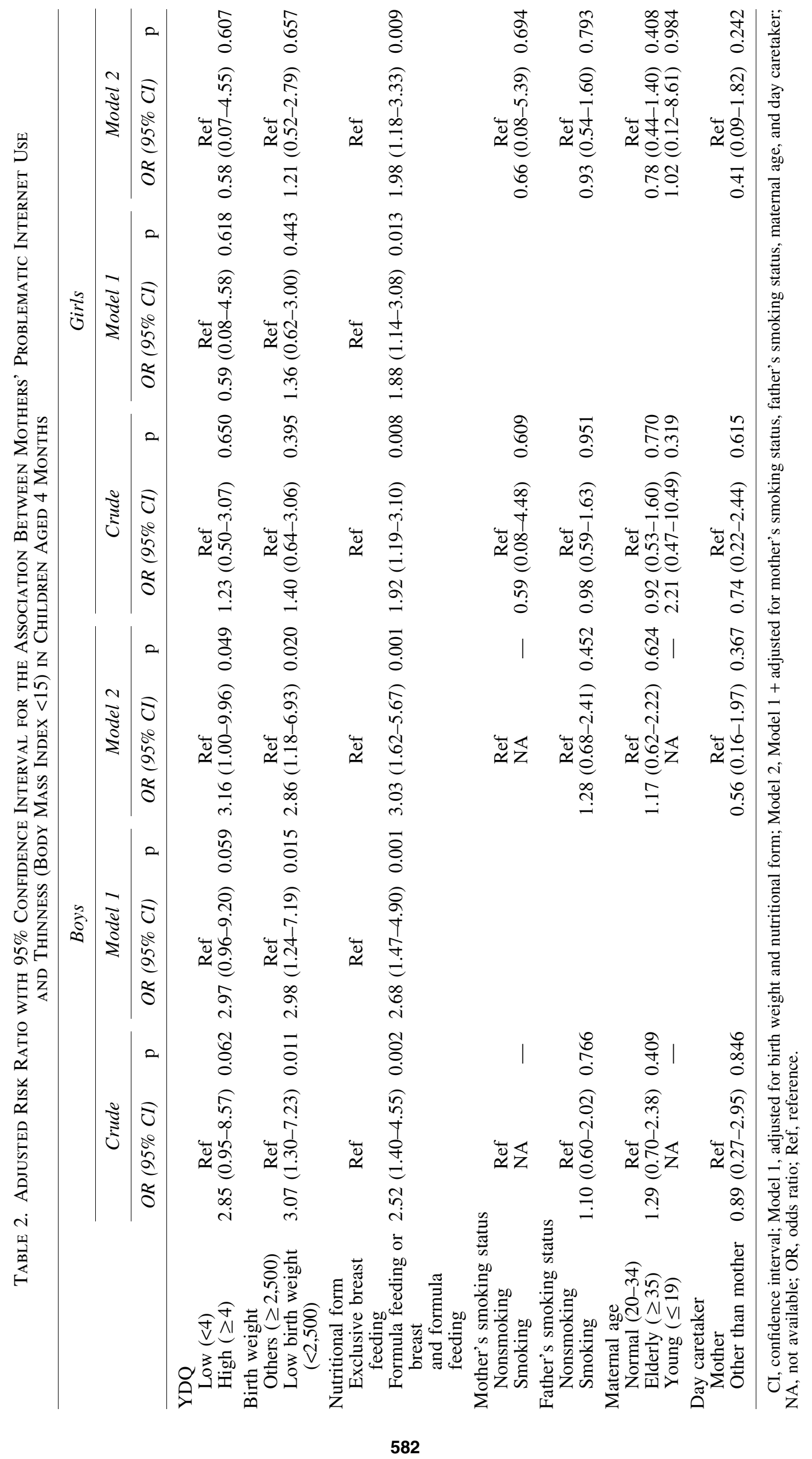




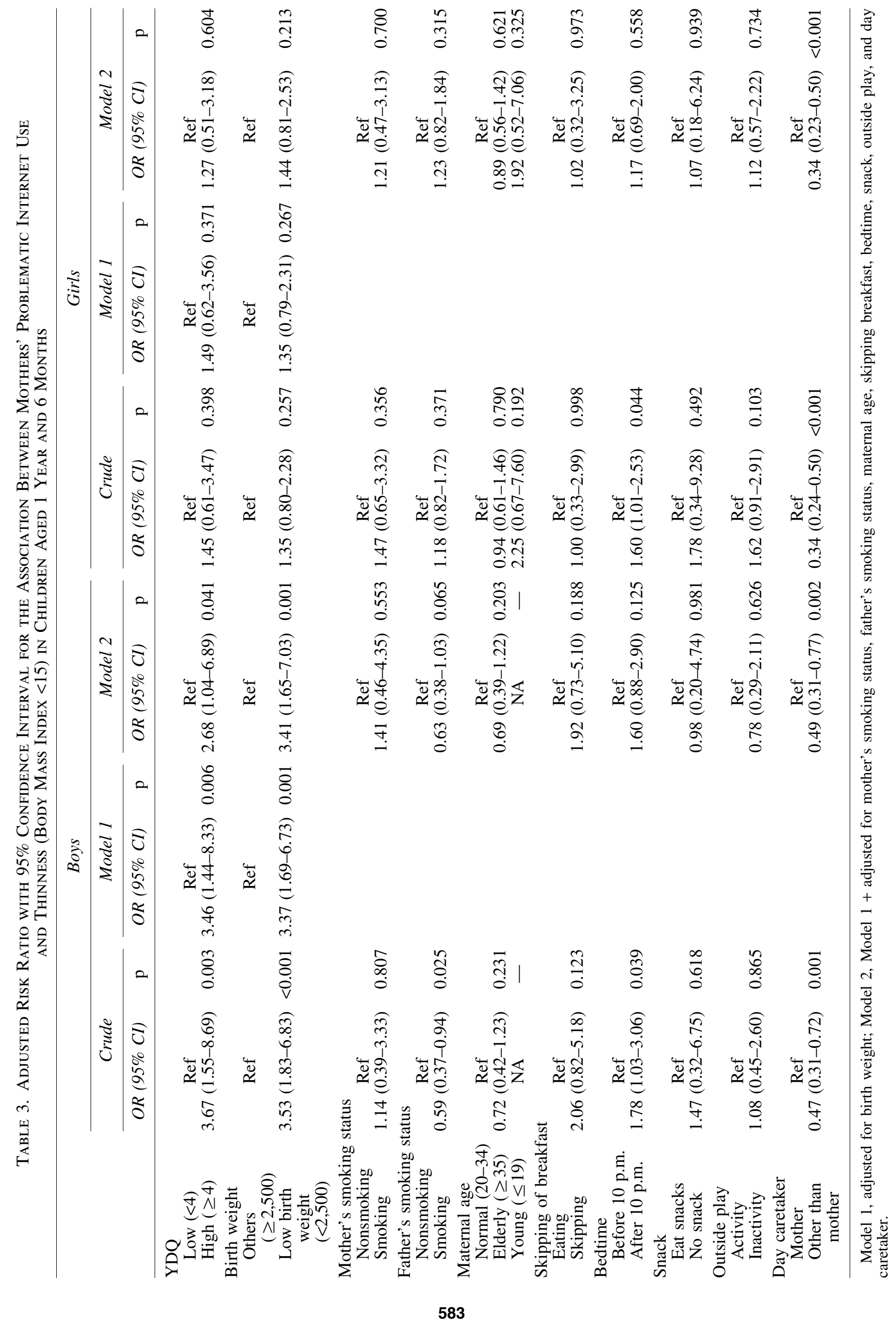




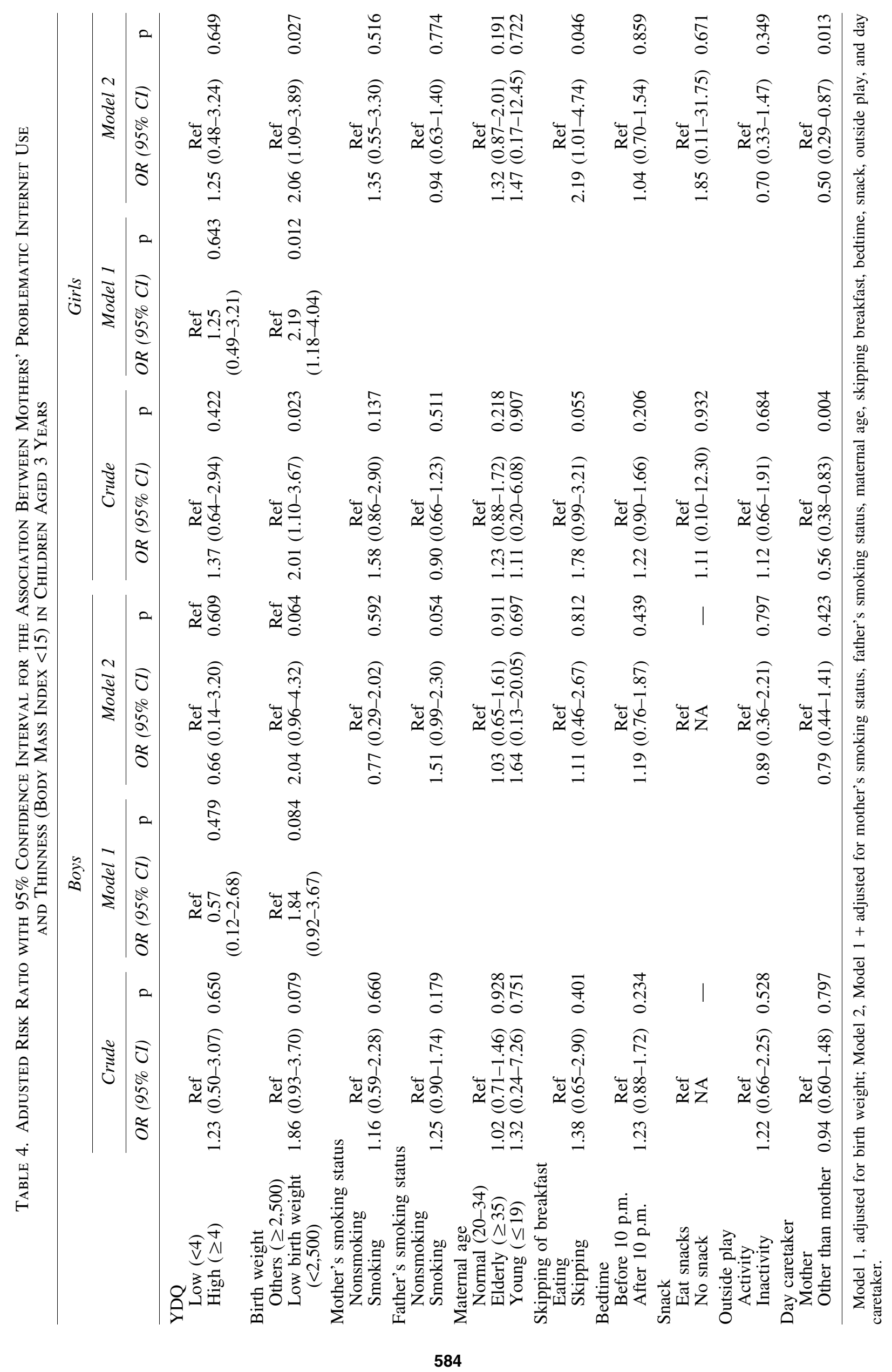


further possibilities, for example, the same association in other age groups or an association between mothers' PIU and obesity. Third, PIU has been reported to be associated with mental disorders, such as attention-deficit/hyperactivity disorder (ADHD), depression, obsessive symptoms, and hostility, ${ }^{28,55-58}$ with several previous studies observing a particularly close association between PIU and ADHD. ${ }^{28,57}$ Although it was difficult to exclude mothers with ADHD in our study, the analysis was performed without those using infant homes, suggesting that mothers with parenting difficulties because of severe mental symptoms were excluded. Fourth, we did not use the International Obesity Task Force thinness grades ${ }^{59}$ or World Health Organization $z$-scores $(<-2 S D),{ }^{37,60}$ which are international criteria for thinness among children, thereby making international comparisons difficult. However, as measurement of the height of children younger than 2 years is prone to errors, screening was performed for those exhibiting a tendency toward thinness, which requires intervention to the extent that clinical significance may be achieved by assessing the condition using standard reference values.

Although such limitations were present, the importance of this study is that it suggests that mothers' PIU indirectly leads to thinness in their children. Internet use by pregnant women and mothers has been demonstrated to be a useful method to collect health information and develop appropriate health-related behaviors ${ }^{61-65}$; however, this study hypothesizes that mothers' PIU increases the risk of health impairment in their children. In particular, the thinness of children was reported to be associated with increased risks of infectious disease, poorer cognitive performance, an$\mathrm{d}$ /or lower school grades, and is a risk factor for diabetes and cardiovascular disease during adulthood. ${ }^{66}$ The provision of health guidance for mothers to appropriately use the Internet may be effective for promoting the healthy growth and development of their children. As future research perspectives, it may be necessary to further clarify the association between mothers' PIU and their children's injuries, dental caries, or other health problems, and the influence of mothers' PIU on the children's health when they become adolescents to confirm whether mothers' PIU increases the risk of health problems in their children. Based on the results of these future studies, it may be possible to establish a system to screen for mothers' PIU during health examinations for infants, to explain to mothers with PIU that their condition may negatively affect their children's growth and development, and to caution them about excessive Internet use.

\section{Conclusions}

Mothers' PIU was associated with thinness in boys aged 4 months or 1.5 years. To understand this finding further, the limitations of this study need to be resolved. Moreover, future surveys should examine the association between mothers' PIU and their children's body size in more detail.

\section{Acknowledgment}

The authors thank the public health nurses in Matsue city for their cooperation.

\section{Author Disclosure Statement}

All authors have completed the ICMJE uniform disclosure form and declare: no support from any organization for the submitted article, no financial relationships with any organizations that may have an interest in the submitted article in the previous 3 years, and no other relationships or activities that may have influenced the submitted article.

\section{Funding Information}

This article was supported by JSPS KAKENHI (Grant No. JP 18K10605).

\section{References}

1. Young KS. Psychology of computer use: XL. Addictive use of the Internet: a case that breaks the stereotype. Psychological Reports 1996; 79:899-902.

2. Laconi S, Rodgers RF, Chabrol H. The measurement of Internet addiction: a critical review of existing scales and their psychometric properties. Computers in Human Behavior 2014; 41:190-202.

3. Lopez-Fernandez O, Freixa-Blanxart M, Honrubia-Serrano ML. The problematic Internet entertainment use scale for adolescents: prevalence of problem Internet use in Spanish high school students. Cyberpsychology Behavior and Social Networking 2013; 16:108-118.

4. Nikolaidou M, Fraser DS, Hinvest N. Physiological markers of biased decision-making in problematic Internet users. Journal of Behavioral Addictions 2016; 5:510-517.

5. Liu T, Potenza MN. Problematic Internet use: clinical implications. CNS Spectrums 2007; 12:453-466.

6. Kim JH, Lau CH, Cheuk KK, et al. Brief report: predictors of heavy Internet use and associations with healthpromoting and health risk behaviors among Hong Kong University students. Journal of Adolescence 2010; 33:215220.

7. Park S, Lee Y. Associations of body weight perception and weight control behaviors with problematic Internet use among Korean adolescents. Psychiatry Research 2017; 251: 275-280.

8. Berkey CS, Rockett HR, Colditz GA. Weight gain in older adolescent females: the Internet, sleep, coffee, and alcohol. The Journal of Pediatrics 2008; 153:635-639.

9. Canan F, Yildirim O, Ustunel TY, et al. The relationship between Internet addiction and body mass index in Turkish adolescents. Cyberpsychology Behavior and Social Networking 2014; 17:40-45.

10. Bakken IJ, Wenzel HG, Götestam KG, et al. Internet addiction among Norwegian adults: a stratified probability sample study. Scandinavian Journal of Psychology 2009; 50:121-127.

11. Zadra S, Bischof G, Besser B, et al. The association between Internet addiction and personality disorders in a general population-based sample. Journal of Behavioral Addictions 2016; 5:691-699.

12. de Vries HT, Nakamae T, Fukui K, et al. Problematic Internet use and psychiatric co-morbidity in a population of Japanese adult psychiatric patients. BMC Psychiatry 2018; 18:9.

13. Cheng $\mathrm{C}, \mathrm{Li} \mathrm{AY}$. Internet addiction prevalence and quality of (real) life: a meta-analysis of 31 nations across seven world regions. Cyberpsychology Behavior and Social Networking 2014; 17:755-760. 
14. Fujioka N, Itose $\mathrm{S}$, Otake R, et al. The influence that Internet use of the 1-year old child's mother gives to the childcare feelings. Maternal Health 2015; 56:128-136. [in Japanese]

15. Young KS. (1998) Caught in the net: how to recognize the signs of Internet addiction-and a winning strategy for recovery. New York: Wiley, pp. 30-34.

16. Alshehri A, Azahrani H, Alotaibi M. Internet addiction among Taif university students and its association with psychiatric co-morbidities. Merit Research Journal of Medicine and Medical Sciences 2015; 3:536-544.

17. Barayan SS, Al Dabal BK, Abdelwahab MM, et al. Healthrelated quality of life among female university students in Dammam district: is Internet use related? Journal of Family and Community Medicine 2018; 25:20-28.

18. Desouky Del-S, Abdellatif Ibrahem R. Internet addiction and psychological morbidity among Menoufia University Students, Egypt. American Journal of Public Health Research 2015; 3:192-198.

19. Frangos CC, Frangos CC, Kiohos AP. Internet addiction among Greek University Students: demographic associations with the Phenomenon, using the Greek version of Young's Internet addiction test. International Journal of Economic Sciences and Applied Research 2010; 3:49-74.

20. Cao F, Su L. Internet addiction among Chinese adolescents: prevalence and psychological features. Child: Care, Health and Development 2007; 33:275-281.

21. Oka Y, Yamamoto R, Horiuchi F, et al. (2015) Health Labor Sciences Research Grant (2015 FY), Comprehensive Research Project for Developing Healthy Next Generation: Current Status of Sleep and Use of Information and Communication Equipment in Preschool Children and Early Intervention for Resulting Problems-Development of Health Guidance manual-[in Japanese]. https://mhlw-grants .niph.go.jp/niph/search/NIDD00.do?resrchNum=201506010A (accessed June 4, 2019).

22. Young KS. Internet addiction: the emergence of a new clinical disorder. CyberPsychology \& Behavior 1998; 1:237-244.

23. Gebremedhin S. Multiple births in sub-Saharan Africa: epidemiology, postnatal survival, and growth pattern. Twin Research and Human Genetics 2015; 18:100-107.

24. Mól N, Zasada M, Klimek M, et al. Somatic development and some indices of lipid metabolism in 11-year-old children born with extremely low birth weight $(<1000 \mathrm{~g})$ (long-term cohort study). Developmental Period Medicine 2017; 21:361-368.

25. Bellizzi MC, Dietz WH. Workshop on childhood obesity: summary of the discussion. The American Journal of Clinical Nutrition 1999; 70:173S-175S.

26. Yokoyama T, Kato N, Takimoto H, et al. (2012) Manual for the Assessment of Infants' Physical Growth, $<$ Statistical Analysis Methods and Use for Surveys on the Physical Growth of Infants $>$ supported by a Health Labour Sciences Research Grant FY 2011. [in Japanese]. https://www.niph .go.jp/soshiki/07shougai/hatsuiku/index.files/katsuyou.pdf (accessed June 4, 2019).

27. Wartberg L, Kriston L, Kegel K, et al. Adaptation and Psychometric Evaluation of the Young Diagnostic Questionnaire (YDQ) for parental assessment of adolescent problematic Internet use. Journal of Behavioral Addictions 2016; 5:311-317.

28. Carli V, Durkee T, Wasserman D, et al. The association between pathological Internet use and comorbid psychopathology: a systematic review. Psychopathology 2013; 46:1-13.

29. Johansson A, Götestam KG. Internet addiction: characteristics of a questionnaire and prevalence in Norwegian youth
(12-18 years). Scandinavian Journal of Psychology 2004; 45:223-229.

30. Fisoun V, Floros G, Geroukalis D, et al. Internet addiction in the island of Hippocrates: the associations between Internet abuse and adolescent off-line behaviours. Child and Adolescent Mental Health 2011; 17:37-44.

31. Pearce A, Rougeaux E, Law C. Disadvantaged children at greater relative risk of thinness (as well as obesity): a secondary data analysis of the England National Child Measurement Programme and the UK Millennium Cohort Study. International Journal for Equity in Health 2015; 14: 61.

32. Ządzińska E, Rosset I. Pre-natal and perinatal factors affecting body mass index in pre-pubertal Polish children. Annals of Human Biology 2013; 40:477-484.

33. Gewa CA, Yandell N. Undernutrition among Kenyan children: contribution of child, maternal and household factors. Public Health Nutrition 2012; 15:1029-1038.

34. Best CM, Sun K, de Pee S, et al. Parental tobacco use is associated with increased risk of child malnutrition in Bangladesh. Nutrition 2007; 23:731-738.

35. Chowdhury F, Chisti MJ, Hossain MI, et al. Association between paternal smoking and nutritional status of underfive children attending Diarrhoeal Hospital, Dhaka, Bangladesh. Acta Paediatrica 2011; 100:390-395.

36. Armstrong J, Dorosty AR, Reilly JJ, et al. Coexistence of social inequalities in undernutrition and obesity in preschool children: population based cross sectional study. Archives of Disease in Childhood 2003; 88:671-675.

37. Maken T, Varte LR. Nutritional status of children as indicated by z-scores of the Hmars: a tribe of N.E. India. Antrocom Online Journal of Anthropology 2012; 8:213-227.

38. Dewey KG. Growth characteristics of breast-fed compared to formula-fed infants. Biology of the Neonate 1998; 74 : 94-105.

39. Cheng TS, Kwok MK, Leung GM, et al. The associations of breastfeeding with infant growth and body mass index to 16 years: "children of 1997." Paediatric and Perinatal Epidemiology 2017; 32:200-209.

40. Yeleswarapu BK, Nallapu SS. A comparative study on the nutritional status of the pre-school children of the employed women and the unemployed women in the urban slums of guntur. Journal of Clinical and Diagnostic Research 2012; 6:1718-1721.

41. Costa S, Adams J, Gonzalez-Nahm S, et al. Childcare in infancy and later obesity: a narrative review of longitudinal studies. Current Pediatrics Reports 2017; 5:118-131.

42. Alsharairi NA, Somerset SM. Skipping breakfast in early childhood and its associations with maternal and child BMI: a study of 2-5-year-old Australian children. European Journal of Clinical Nutrition 2016; 70:450-455.

43. O'Dea JA, Amy NK. Perceived and desired weight, weight related eating and exercising behaviours, and advice received from parents among thin, overweight, obese or normal weight Australian children and adolescents. International Journal of Behavioral Nutrition and Physical Activity 2011; 8:68.

44. Kagamimori S, Yamagami T, Sokejima S, et al. The relationship between lifestyle, social characteristics and obesity in 3-year-old Japanese children. Child: Care, Health and Development 1999; 25:235-247.

45. Ferrar K, Olds T. Thin adolescents: who are they? What do they do? Socio-demographic and use-of-time characteristics. Preventive Medicine 2010; 51:253-258. 
46. Fukuda Y, Nakamura K, Takano T. Socioeconomic Pattern of Smoking in Japan: income inequality and gender and age differences. Annals of Epidemiology 2005; 15:365-372.

47. Lam LT. Risk factors of Internet addiction and the health effect of Internet addiction on adolescents: a systematic review of longitudinal and prospective studies. Current Psychiatry Reports 2014; 16:508.

48. Ko CH, Yen JY, Yen CF, et al. The association between Internet addiction and psychiatric disorder: a review of the literature. European Psychiatry 2012; 27:1-8.

49. Lam LT. Internet gaming addiction, problematic use of the Internet, and sleep problems: a systematic review. Current Psychiatry Reports 2014; 16:444.

50. Whitaker KL, Jarvis MJ, Boniface D, et al. The intergenerational transmission of thinness. Archives of Pediatrics \& Adolescent Medicine 2011; 165:900-905.

51. Kato R, Kubota M, Higashiyama Y, et al. Longitudinal study of thinness from birth to early childhood: the association with parental thinness. Acta Paediatrica 2014; 103 : 1285-1289.

52. Tennefors C, Coward WA, Hernell O, et al. Total energy expenditure and physical activity level in healthy young Swedish children 9 or 14 months of age. European Journal of Clinical Nutrition 2003; 57:647-653.

53. Eriksson B, Henriksson H, Löf M, et al. Body-composition development during early childhood and energy expenditure in response to physical activity in 1.5-y-old children. The American Journal of Clinical Nutrition 2012; 96:567573.

54. Butte NF, Wong WW, Hopkinson JM, et al. Energy requirements derived from total energy expenditure and energy deposition during the first $2 \mathrm{y}$ of life. The American Journal of Clinical Nutrition 2000; 72:1558-1569.

55. Yen JY, Ko CH, Yen CF, et al. The comorbid psychiatric symptoms of Internet addiction: attention deficit and hyperactivity disorder (ADHD), depression, social phobia, and hostility. Journal of Adolescent Health 2007; 41:93-98.

56. Ho RC, Zhang MW, Tsang TY, et al. The association between Internet addiction and psychiatric co-morbidity. BMC Psychiatry 2014; 14:183.

57. Ko CH, Yen JY, Chen CS, et al. Predictive values of psychiatric symptoms for Internet addiction in adolescents: a 2-year prospective study. Archives of Pediatrics \& Adolescent Medicine 2009; 163:937-943.

58. Lam LT, Peng ZW. Effect of pathological use of the Internet on adolescent mental health: a prospective study.
Archives of Pediatrics \& Adolescent Medicine 2010; 164: 901-906.

59. Cole TJ, Flegal KM, Nicholls D, et al. Body mass index cut offs to define thinness in children and adolescents: international survey. BMJ_British Medical Journal 2007; 335: 194.

60. World Health Organization (WHO). (2006) Multicentre Growth Reference Study Group. WHO child growth standards: length/height-for-age, weight-for-age, weight-forlength, weight-for-height and body mass index-for-age: methods and development. Geneva, Switzerland: World Health Organization.

61. Peragallo Urrutia R, Berger AA, Ivins AA, et al. Internet use and access among pregnant women via computer and mobile phone: implications for delivery of perinatal care. JMIR mHealth and uHealth 2015; 3:e25.

62. Huberty J, Dinkel D, Beets MW, et al. Describing the use of the Internet for health, physical activity, and nutrition information in pregnant women. Maternal and Child Health Journal 2013; 17:1363-1372.

63. Lagan BM, Sinclair M, Kernohan WG. A Web-based survey of midwives' perceptions of women using the Internet in pregnancy: a global phenomenon. Midwifery 2011; 27: 273-281.

64. Romano AM. A Changing landscape: implications of pregnant women's Internet use for childbirth educators. The Journal of Perinatal Education 2007; 16:18-24.

65. Logsdon MC, Bennett G, Crutzen R, et al. Preferred health resources and use of social media to obtain health and depression information by adolescent mothers. Journal of Child and Adolescent Psychiatric Nursing 2014; 27:163-168.

66. Victora CG, Adair L, Fall C, et al. Maternal and child undernutrition: consequences for adult health and human capital. Lancet 2008; 371:340-357.

Address correspondence to: Assoc. Prof. Aya Sakakihara

Community Health Nursing Faculty of Medicine Shimane University 89-1 Enya-cho Izumo, Shimane 693-8501 Japan

E-mail: aya@med.shimane-u.ac.jp 